DOI: https://doi.org/10.15407/rpra26.01.074

\author{
V. N. MELNIK ${ }^{1}$, A. A. KONOVALENKO ${ }^{1}$, V. V. DOROVSKYY ${ }^{1}$, \\ A. LECACHEUX ${ }^{2}$, H. O. RUCKER ${ }^{3}$ and M. V. SHEVCHUK ${ }^{1}$ \\ ${ }^{1}$ Institute of Radio Astronomy, \\ National Academy of Sciences of Ukraine, \\ 4, Mystetstv St., Kharkiv, 61002, Ukraine \\ E-mail:melnik@rian.kharkov.ua \\ ${ }^{2}$ LESIA, Observatoire de Paris, CNRS, PSL/SU/UPMC/UPD/SPC, \\ 5, Place Jules Janssen, Meudon, F-92195, France \\ ${ }^{3}$ Komission für Astronomie, \\ Österreichischen Akademie der Wissenschaften, \\ 6, Schmiedlstrasse, Graz, 8042, Austria
}

\title{
EXPLORATION OF THE SOLAR DECAMETER RADIO EMISSION WITH THE UTR-2 RADIO TELESCOPE
}

Purpose: The overview of the scientific papers devoted to the study of the solar decameter radio emission with the world's largest UTR-2 radio telescope (Ukraine) published for the last 50 years.

Design/methodology/approach: The study and analysis of the scientific papers on both sporadic and quiet (thermal) radiation of the Sun recorded with the UTR-2 radio telescope at the decameter wavelength range.

Findings: The most significant observational and theoretical results of the solar radio emission studies obtained at the Institute of Radio Astronomy of the National Academy of Sciences of Ukraine for the last 50 years are given.

Conclusions: For the first time, at frequencies below $30 \mathrm{MHz}$, the Type II bursts, Type IV bursts, S-bursts, drift pairs and spikes have been recorded. The dependences of these bursts parameters on frequency within the frequency band of 9 to $30 \mathrm{MHz}$ were obtained. The models of their generation and propagation were suggested. Moreover, for the first time the fine time-frequency structures of the Type III bursts, Type II bursts, Type IV bursts, U-and J-bursts, S-bursts, and drift pairs have been observed due to the high sensitivity and high time-frequency resolutions of the UTR-2 radio telescope. The super-fine structure of Type II bursts with a "herringbone" structure was identified, which has never been observed before. New types of bursts were discovered: "caterpillar" bursts, "dog-leg" bursts, Type III bursts with decay, Type III bursts with changing drift rate sign, Type III-like bursts, $\mathrm{Jb}$ - and Ub-bursts, etc. An interpretation of the unusually high drift rates and drift rates with alternating signs of the Type III-like bursts was suggested. Based on the dependence of spike durations on frequency, the coronal plasma temperature profile at the heliocentric heights of $1.5-3 R_{S}$ was determined.

Usage of the heliographic and interferometric methods gave the possibility to start studies of the spatial characteristics - sizes and locations of the bursts emission sources. Thus, it was shown that at the decameter band, the Type III burst durations were defined by the emission source linear sizes, whereas the spike durations were governed by the collision times in the source plasma. It was experimentally proved that the effective brightness temperatures of the sources of solar sporadic radio emission at the decameter band may reach values of $10^{14}-10^{15} \mathrm{~K}$. In addition, it was found that the radii of the quiet Sun at frequencies 20 and $25 \mathrm{MHz}$ are close to the distances from the Sun at which the local plasma frequency is equal to the corresponding observed frequency of radio emission in the Baumbach-Allen model.

Key words: UTR-2, Sun, decameter radio emission, radio bursts, corona

\section{Introduction}

Solar observations with the UTR-2 radio telescope (Ukraine) have begun right after its commissioning in 1970. Before 2000, all observations were made at a limited number of fixed frequencies, typically at 25 , 20, 16, 12.5, and 6.25 MHz. This fact significantly narrowed down a variety of studied events mainly to Type III bursts, drift pairs and thermal radio emission of the Sun. The possibility to observe the Sun in the heliographic mode allowed to determine the spatial characteristics of the received radio emission sources - their angular sizes and locations in the corona. Equipping of the UTR-2 radio telescope with the 30-channel and 60-channel radiometers and especially with a broadband digital spectrum polarimeter (DSP) of high temporal and frequency resolutions considerably improved the instrument's capability. Thus, a number of events, such as Type II and Type IV bursts, U- and J-bursts, S-bursts and spikes as well as their fine structure were first observed at the frequency below $30 \mathrm{MHz}$. Carrying out the observations in an interferometric mode by using some separate sections of the UTR-2 radio telescope opens new possibilities in studying the events occurring in the corona at distances of $1.5-3 R_{S}$ ( $R_{S}$ is the solar radius). 
Below, the main results obtained from observations of the solar radio emission with the UTR-2 radio telescope for the last 50 years are presented.

\section{Type III Bursts}

The Type III bursts are the most striking manifestation of the sporadic radio emission of the Sun. They were classified as a separate class of solar bursts by J. P. Wild in 1950. Since then, much attention has been paid to the study of this phenomenon. These bursts can be observed in a wide frequency band from $1 \mathrm{GHz}$ down to tens of kilohertz. The flux densities of their emission can reach values of $10^{5}$ s.f.u. (1 s.f.u. $=10^{-22} \mathrm{~W} \cdot \mathrm{m}^{-2} \cdot \mathrm{Hz}^{-1}$ ). The burst typical dynamic spectrum looks like a track of radio emission drifting from high to low frequencies with the characteristic rate. The frequency drift rate depends on frequency and decreases towards lower frequencies. On the contrary, the durations of Type III bursts increase with frequency decrease. It is commonly accepted that the Type III bursts are generated by electron beams accelerated in solar flares and moving along the open magnetic field lines away from the Sun.

Observations of the Type III bursts with the UTR-2 radio telescope began right after its commissioning and have been continuing until now. Properties of these bursts have been studied in two directions. The main direction is the determination of the Type III bursts spectral characteristics within the frequency range from 8 to $32 \mathrm{MHz}$. And the second one is the determination of the spatial properties of the bursts sources, namely their locations and sizes at different frequencies. The last task is solved by using heliographic and interferometric methods.

In 70-90s, the research work at the UTR-2 radio telescope was mainly focused on studying the properties of standard Type III bursts at fundamental and harmonic frequencies, their drift rates, durations and fluxes. Until 2000s, all observations were made at fixed frequencies, typically at 25, 12.5, and in some rare cases at $6.25 \mathrm{MHz}$. The locations and sizes of Type III bursts sources were also determined at these frequencies. It was found that the drift rates of decameter Type III bursts in most cases were equal to $1-3 \mathrm{MHz} / \mathrm{s}[1,2]$, whereas the bursts durations were of a few seconds. The drift rate dependences on frequency for the fundamental and harmonic bursts were found to be similar.
In addition, it was shown that during the 11-year cycle of observations (1973-1984) the mean drift rates of the Type III bursts remained the same [2]. Moreover, the drift rate dependence on frequency $\dot{f}$ for a large number of bursts follows the power law as $\dot{f} \sim f^{1.7}$. Comparison of this dependence with the analogous dependence for the hectometer bursts leads us to the conclusion that the hectometer Type III bursts are most likely generated at the fundamental frequency. Similarity of the drift rate dependence on frequency in the IIIb-III pairs (description of the Type IIIb bursts see below) allowed to conclude that the components of the pairs were harmonically related [3]. Properties of the individual Type III bursts observed in storms were analyzed for the first time in [4]. The authors showed that the observed storm was associated with an active region, which was moving across the solar disk from East towards West. It was found that the average drift rate of these Type III bursts depended substantially on the active region location on the solar disk. The highest drift rates were recorded on the days when an active region was located near the central meridian, whereas the lowest value (approximately twice as low) was observed when the active regions were close to the solar limb. This fact pointed that in the first case the Type III bursts were generated at the fundamental frequency, while in the second one, the harmonic emission took place. This conclusion became an important argument in favour of the plasma emission mechanism of the Type III bursts, since according to this mechanism, the fundamental radio emission source has a narrow radiation pattern in the direction of the fast electrons movement, whereas the harmonic emission source radiates in a much wider pattern, and thus can be observed when the electron beams travel at large angles to the observer.

Using the observational data obtained with the UTR-2 radio telescope at 25, 12.5, and $6.25 \mathrm{MHz}$, the delays between fundamental and harmonic components of the Type III harmonic pairs observed at the same frequency and at the harmonically related ones were analysed. Within the framework of the plasma emission mechanism there should be the delay differences due to different group velocities of the fundamental and harmonic emissions [5]. The analysis showed that this difference became noticeable when the speed of the Type III exciter was equal or less than $0.1 c$ ( $c$ is the speed of light). 
If the exciter was faster, the delay difference became negligible. This was one more confirmation of the hypothesis that the typical velocities of the Type III bursts sources equal to $0.2-0.3 c$.

First heliographic observations of 130 Type III bursts with the UTR-2 radio telescope [6] showed that the fundamental emission source size was smaller than $10^{\prime}$ at $25 \mathrm{MHz}$. At the same time, the harmonic emission source size equalled to $20^{\prime}$ at $25 \mathrm{MHz}$ and $<40^{\prime}$ at $12.5 \mathrm{MHz}$. The remarkable fact is a spatial coincidence of the fundamental and harmonic emission sources in the plane of sky.

Yet more important result was obtained by Abranin et al. [4]. The authors determined the locations of the fundamental and harmonic emission sources of the Type III bursts at $25 \mathrm{MHz}$ during the Type III storm, when the associated active region was crossing the solar disk from the limb towards the central meridian. The heliocentric distance appeared to be $2.3 R_{S}$, when the active region was on the eastern limb, and $1.8 R_{S}$ for the active region central location. Moreover, the locations of the fundamental and harmonic emission sources at $25 \mathrm{MHz}$ coincided. The authors considered this observational fact as an evidence that the Type IIIb bursts were precursors of the Type III bursts.

After the UTR-2 radio telescope was equipped with the multi-channel receivers of high spectral and temporal resolutions, the capabilities of the instrument in studying the Type III bursts were improved considerably. Thus, in 2001-2002, the Type III bursts with the fine frequency-time structure were observed [7]. This fine structure had an appearance of short sub-bursts, whose drift rates were smaller, equal or greater than that of the "parent" burst. Occasionally, the fine structures with the negative and positive frequency drift rates were simultaneously observed within one Type III burst. Durations of these subbursts equaled to about $1 \mathrm{~s}$, i.e. several times shorter than that of the "parent" burst. Sometimes, the solar S-bursts and drift pairs (discussion of these bursts see below) were observed on the background of the Type III bursts and were strictly limited by the Type III burst boundaries.

In 2002-2004, more than 1000 Type III bursts with abnormally high drift rates were recorded [8]. These bursts were called the Type III-like bursts. Frequency drift rates of typical decameter Type III bursts did not exceed $4 \mathrm{MHz} / \mathrm{s}$. The Type III-like bursts had the drift rates of about 5-10 MHz/s. In rare cases, the drift rates of these bursts reached the value of up to $42 \mathrm{MHz} / \mathrm{s}$. The Type III-like bursts durations were about $1 \mathrm{~s}$, being several times shorter than in the standard Type III bursts. These bursts occurred on the days when the associated active region was located near the central meridian. Their fluxes as a rule did not exceed a few tens of s.f.u. High drift rates of Type III-like bursts could not be explained by the increased exciter speed, which should be superluminal in this case. Thus, the model was suggested in which abnormally high drift rates could be observed when the exciter speed was close to the group velocity of the electromagnetic wave. If the exciter speed is slightly lower than the group velocity, Type III-like burst with high but negative drift rate is observed. And if the exciter speed exceeds the group velocity the drift rate may turn to positive. Melnik et al. [9] reported about observations of the Type III bursts with changing the drift rate sign. In the model suggested, this fact meant that the fast electron beams successively moved through the regions of different temperature, where the electromagnetic wave group velocity dependent on temperature could be higher or lower than the exciter velocity resulting in the drift rate sign change.

In observational data of July-August 2002, the powerful (fluxes $>10^{3}$ s.f.u.) Type III bursts (Fig. 1(a)) were identified and studied [10] in order to find their specific properties compared to standard Type III bursts, whose fluxes did not exceed 1000 s.f.u. About 400 such bursts were selected for deep analysis. Their characteristic properties were as follows. Frequency drift rate increased with frequency almost linearly following the equation $\dot{f}=A f$ with factor $A$ ranging from 0.08 to $0.12 \mathrm{~s}^{-1}$. Thus, the absolute drift rates varied from $1.2 \mathrm{MHz} / \mathrm{s}$ at $10 \mathrm{MHz}$ to $3.6 \mathrm{MHz} / \mathrm{s}$ at $30 \mathrm{MHz}$. Generally speaking, such drift rates were inherent in normal Type III bursts. Durations $D$ of the powerful Type III bursts depended on frequency approximately like $D=60 f^{-2 / 3}$, which is also typical for the normal Type IIIs. No systematic dependence of the fluxes of powerful Type III bursts on frequency was found. There were cases when fluxes were monotonically increasing with the frequency decrease, as well as cases of the opposite trend and even mixed dependences. The occurrence rate of powerful Type III bursts didn't show any dependence on the longitude of the associated active regions, which were equally distributed between $-60^{\circ}$ and $+60^{\circ}$. 

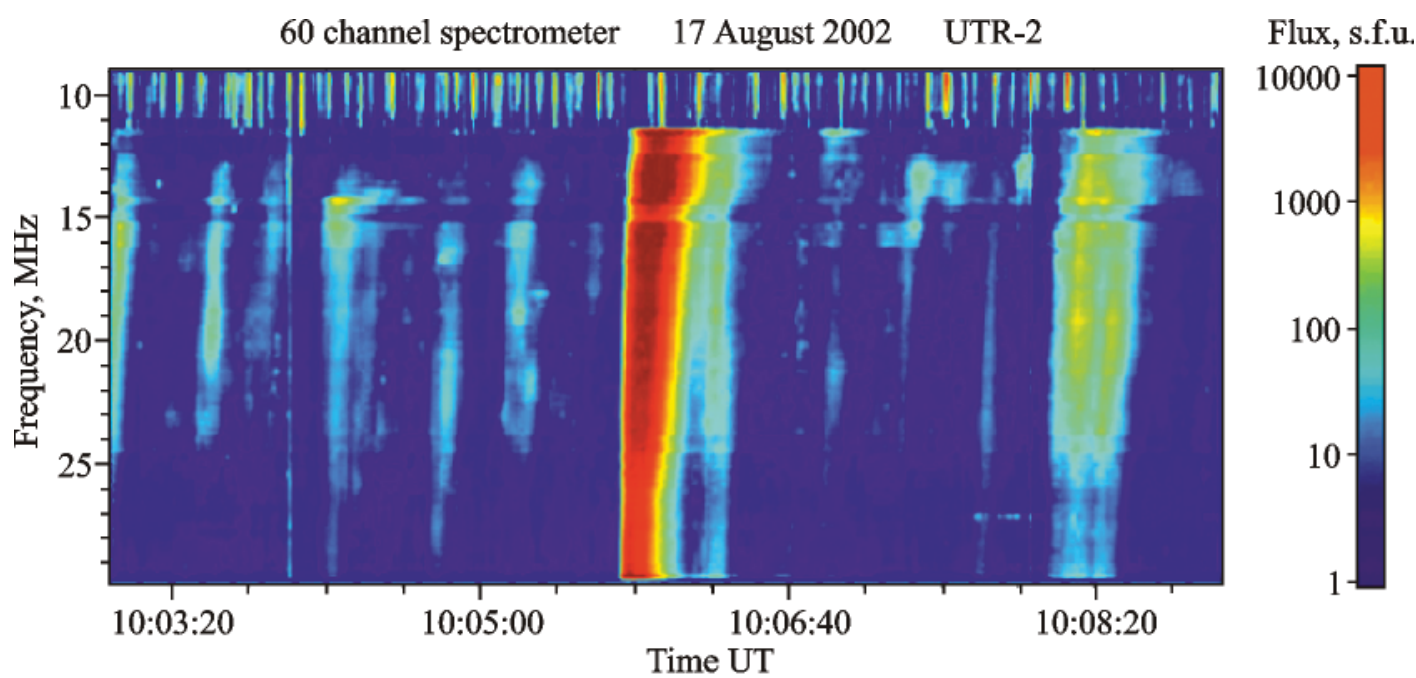

(a)

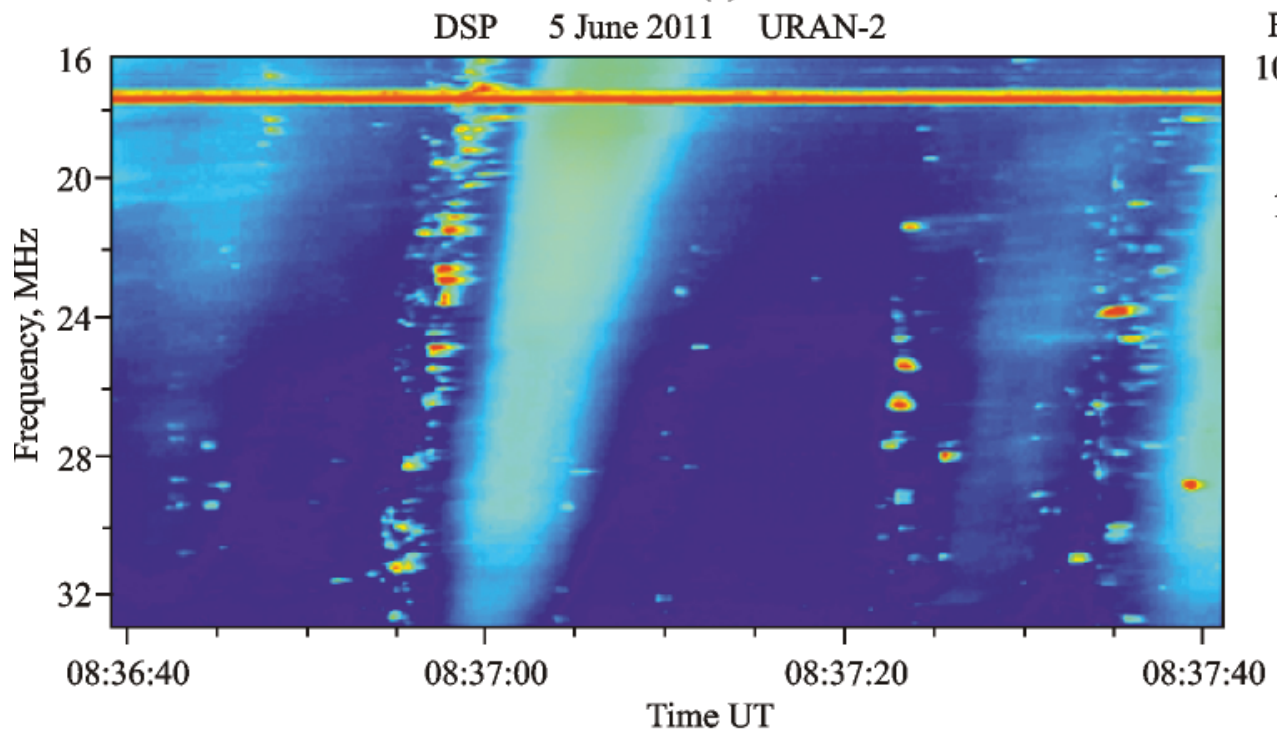

Flux, s.f.u.
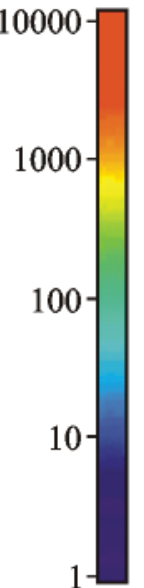

(b)

Fig. 1. Powerful Type III burst (10:06 UT) on the background of Type III bursts storm $(a)$ and Type IIIb-III pair (8:37 UT) accompanied with chaotically spread short and narrow-band spikes $(b)$

From the extended UTR-2 observational data of 2002-2006, the unusual Type III bursts having noticeable jump in their drift rates dependence on frequency were selected. The drift rates of such bursts in general monotonically decreased with the frequency decrease similarly to the normal Type III bursts until the frequency below which the dependence steepness stepwise decreased by several times of magnitude [11]. These bursts were called the "dogleg" bursts. The jumps in a drift rate were mainly observed at frequencies between 12 and $21 \mathrm{MHz}$ with the maximum occurrence rate at the frequency of $20 \mathrm{MHz}$. Since the exciter speed cannot change stepwise by such a value, this phenomenon may hap- pen when the burst exciter successively crossed the regions with substantially different coronal plasmas, including those with different inhomogeneities.

On basis of UTR-2 data, the model of Type III bursts emission propagation from their sources to the observer [12] was worked out. The model showed that the standard Type III bursts are generated by the electron beams moving with velocities of about $6 \cdot 10^{9} \mathrm{~cm} / \mathrm{s}$, while the electrons with velocities of $10^{10} \mathrm{~cm} / \mathrm{s}$ were responsible for the fast Type III burst generation. Moreover, it was shown that the standard Type III bursts durations were determined by the spatial sizes of the emission sources. According to the model, the drift rate of Type III 
burst decreased with increasing of the longitudinal angle at which the electron beam propagated with respect to the observer. The observed fine structure of the Type III bursts in this case could be explained by an inhomogeneity of the density distribution inside the associated electron beam.

In addition to heliographic observations made with the UTR-2 radio telescope, the interferometric observations were also carried out. In such observations, the UTR-2 antenna separate sections formed the interferometer baselines. The latters allowed to determine the decameter bursts sources sizes ranging from several arc minutes up to one degree. In May-June 2014, the interferometric observations of rather powerful Type III bursts associated with the on-limb active regions were made at fixed frequencies of 20 and $25 \mathrm{MHz}$ [13]. The sizes of the bursts sources at the frequencies of 20 and $25 \mathrm{MHz}$ were found to equal $27-29^{\prime}$ and $20-22^{\prime}$. The sources distances at these frequencies were $45-49^{\prime}$ and $39-42^{\prime}$ respectively. This counted in favor of bursts generation at the harmonic frequency in the Newkirk corona model. The results obtained allowed to determine the effective brightness temperatures of the emission, which appeared to be $10^{9}-5 \cdot 10^{10} \mathrm{~K}$. Comparison of the Type III bursts durations with the sizes of their sources resulted in determination of the linear velocities of the exciters, which appeared to be $0.2-0.3 c$.

\section{Type IIIb-IIId Bursts}

Bazelyan et al. [14] have identified two additional sub-classes of normal Type III bursts, the so called Type IIIb (Fig. 1(b)) and Type IIId bursts. By the general appearance and frequency drift rate these bursts resembled normal Type III bursts, however, unlike the former, they consist of a fine structure in the form of stria bursts. Striae are short and narrow-band bursts, which can be observed either as single bursts or as doublets and triplets. In addition, the striae themselves are divided into normal and diffuse bursts. According to [15], normal striae had durations of about $1 \mathrm{~s}$, spectral bandwidth of about $70 \mathrm{kHz}$ and typical drift rates near $-70 \mathrm{kHz} / \mathrm{s}$ at the frequency of $25 \mathrm{MHz}$. At the same time, the diffuse striae did not drift in frequency having durations and bandwidths of $10 \mathrm{~s}$ and $120 \mathrm{kHz}$ respectively. Another difference was the value of frequency split in doublets and triplets, which equaled to $100 \mathrm{kHz}$ for normal striae and $180 \mathrm{kHz}$ for the diffuse ones. Nevertheless the striae of both types can gather in structures, the so called chains of bursts drifting from high to low frequency with the drift rates typical for normal Type III bursts. The chains composed of normal and diffuse striae were called Type IIIb and Type IIId bursts correspondingly.

As a rule, the Type IIIb and Type IIId bursts were observed simultaneously with the normal Type III bursts. However, the Type IIIb bursts often precede the normal Type IIIs forming the so called Type IIIb-III pair (Fig. 1(b)). In turn, the Type IIId bursts usually followed the normal Type III bursts thus making up the Type III-IIId pair. The question of the relation between the bursts in these pairs has been repeatedly raised by a number of authors [14, 16, 17]. Deep analysis of the observational data of different years allowed the authors to show that the instant frequency ratios in the Type IIIb-III pairs varied from 1.65 to 2.35 with an average value being 2.03 . In authors' opinion this fact counted in favor of the assumption that the leading burst in pair was generated at the fundamental and the trailing one at the harmonic frequency. Similar results were obtained for the Type III-IIId pairs. The frequency ratio appeared to be 1.94 pointing out that the Type IIId was likely harmonic component in pair with the normal Type III being fundamental.

Analysis of the Type IIIb-III pairs drift rates showed that the normal Type IIIs drift rates were always noticeably lower than those of the Type IIIb chains when measured at the same frequency. The drift rates of the former were found to be $0.6-1.4 \mathrm{MHz} / \mathrm{s}$ and the latter drifted as $1.0-1.46 \mathrm{MHz} / \mathrm{s}$. In the plasma emission mechanism this fact might evidence that the Type IIIb bursts were generated by faster electron beams as compared to the normal Type III bursts [14].

Observations of the Type IIIb-III pairs in the heliographic mode at the frequency of $25 \mathrm{MHz}$ [18] showed that the angular sizes of the sources of both types of bursts were close and equaled to $20-40^{\prime}$. It was also found that apparent locations of the Type IIIb and III bursts sources practically coincided with mismatches (if any) considerably less than $25^{\prime}$ [6]. Moreover, Abranin et al. [16] noted that the size of the source of an individual stria burst remains constant during the burst lifetime. No systematic dependence of the stria bursts duration on its source size was found. It was just reported that the bursts, whose 
source sizes were $20^{\prime}-50^{\prime}$, had mean duration equal to $0.38-0.59 \mathrm{~s}$.

It was shown that the Type IIIb bursts were predominantly observed simultaneously with the Type III bursts and consisted of a number of separate striae $[19,20]$. The total amount of individual striae in one Type IIIb burst in the frequency range of 8-32 MHz could exceed 95 . In some cases, this amount was so large that it was difficult to distinguish the neighboring striae one from another. The obtained parameters did not differ too much from those reported in [15]: the durations were within the range of $0.46-1.4 \mathrm{~s}$, the spectral bandwidths were about $20-100 \mathrm{kHz}$ and the emission fluxes varied from 20 to 100 s.f.u. However, a considerably wider frequency band of available observational data allowed to determine the dependences of striae durations and bandwidths on frequency. Thus it was found that the straie durations decreased with increasing frequency as $d \sim f^{-1}$, whereas the bandwidths increased as $\Delta f=A f$. On basis of the results obtained and assuming the plasma emission mechanism the authors supposed that the durations and the bandwidths of stria bursts were apparently determined by the temperature and the magnetic field in the place of generation, just as it took place for the decameter spikes [20]. The mean temperature obtained under such assumptions equaled to $0.28 \mathrm{~K}$, and the magnetic field was approximately $1.8 \mathrm{G}$ at the distance of $1.9 R_{S}$.

\section{U- and J-Bursts}

Since the very discovery in 1958 , the solar inverted U-bursts were considered as a subclass of the normal Type III bursts due to similarity of their sources. The main distinct feature of U-bursts is that the accelerated sub-relativistic electron beams move along the closed magnetic field lines, known as coronal loops. The name of these bursts came from the similarity of their dynamic spectra and inverted letter "U" (Fig. 2(a)). Analogously, the bursts with the descending branches being not visible were called the J-bursts. The U- and J-bursts were observed in a wide frequency range from $1 \mathrm{GHz}$ down to hundreds of kilohertz. At the same time, it was reported that these bursts more often occurred in the frequency band of 25-30 MHz and thus could be reliably observed with the UTR-2 radio telescope. It is reasonably believed that the U-bursts with such turn over frequencies can serve as a tool for diagnostics of high coronal loops, which cannot be studied by other methods. Reliable identification of solar $U$ - and J-bursts requires observations in a wide continuous frequency band, that is why these bursts were first observed with the UTR-2 radio telescope only in 2003 after being equipped with new broadband backends [21]. During 2003-2004, about 50 such bursts were observed, among which only 7 events could be identified as the U-bursts. The observed bursts distribution by their turn over frequencies showed that about $90 \%$ of them had turn over frequencies below $24 \mathrm{MHz}$. The U-bursts with well-developed descending legs were exclusively observed as isolated events, while the J-bursts used to gather in groups by $3-10$ bursts. The turnover frequency in a J-bursts group might remain constant for a whole group or steadily decrease with time. The group of three J-bursts with drifting turnover frequencies was observed on 26 June 2004. All bursts in group were morphologically identical and their turnover frequencies were sequentially decreasing with the rate of $-2 \mathrm{kHz} / \mathrm{s}$. This drift rate may point out that the associated with these bursts coronal loop was raising in the corona with the velocity of about $70 \mathrm{~km} / \mathrm{s}$. Such a low velocity of coronal loops raising was identified for the first time.

The U- and J-bursts were often observed in the form of harmonic pair in which the components of the pair represent the emission at fundamental and harmonic frequencies almost simultaneously. The harmonic pairs of the J-bursts analogous to the wellknown Type IIIb-III pairs were observed with the UTR-2 for the first time. In such pairs, the leading burst consisted of narrow band sub-bursts - striae. Such pairs were called the $\mathrm{Jb}-\mathrm{J}$ pairs [21].

Due to the fact that the U- and J-bursts turnover points were unambiguously determined on the timefrequency plane it became possible to determine the real frequency ratio and the time delay between the components of a harmonic pair. Thus, on basis of joint observations with the radio telescopes UTR-2 and GURT (Ukraine) held on 8 August 2012 it was found that the turnover frequencies ratio in the harmonic pair was close to 2 [22] (Fig. 2(a)). In addition, the fundamental component of the pair was delayed by $7 \mathrm{~s}$ with respect to the harmonic one. According to the developed model, the delay occurred due to the low group velocity of the fundamental radio emission while propagating through the dense and hot plasma of the coronal loop. The given model also 


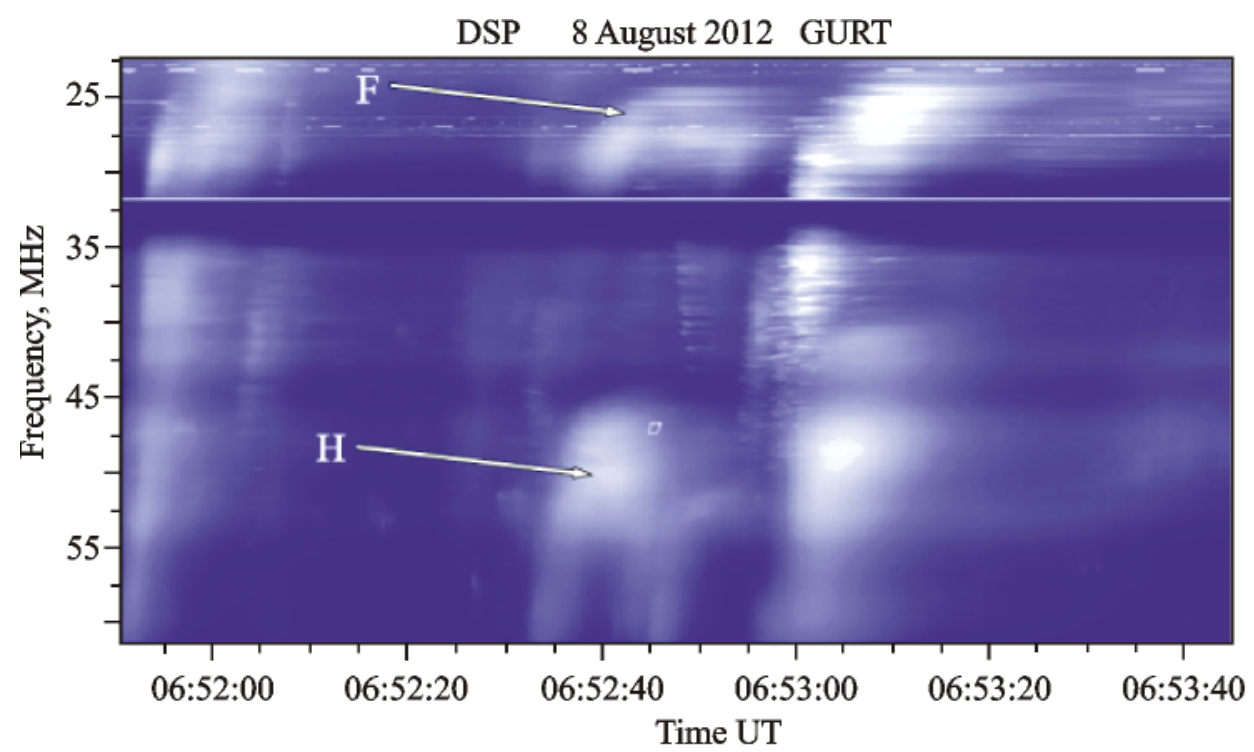

Flux, s.f.u.
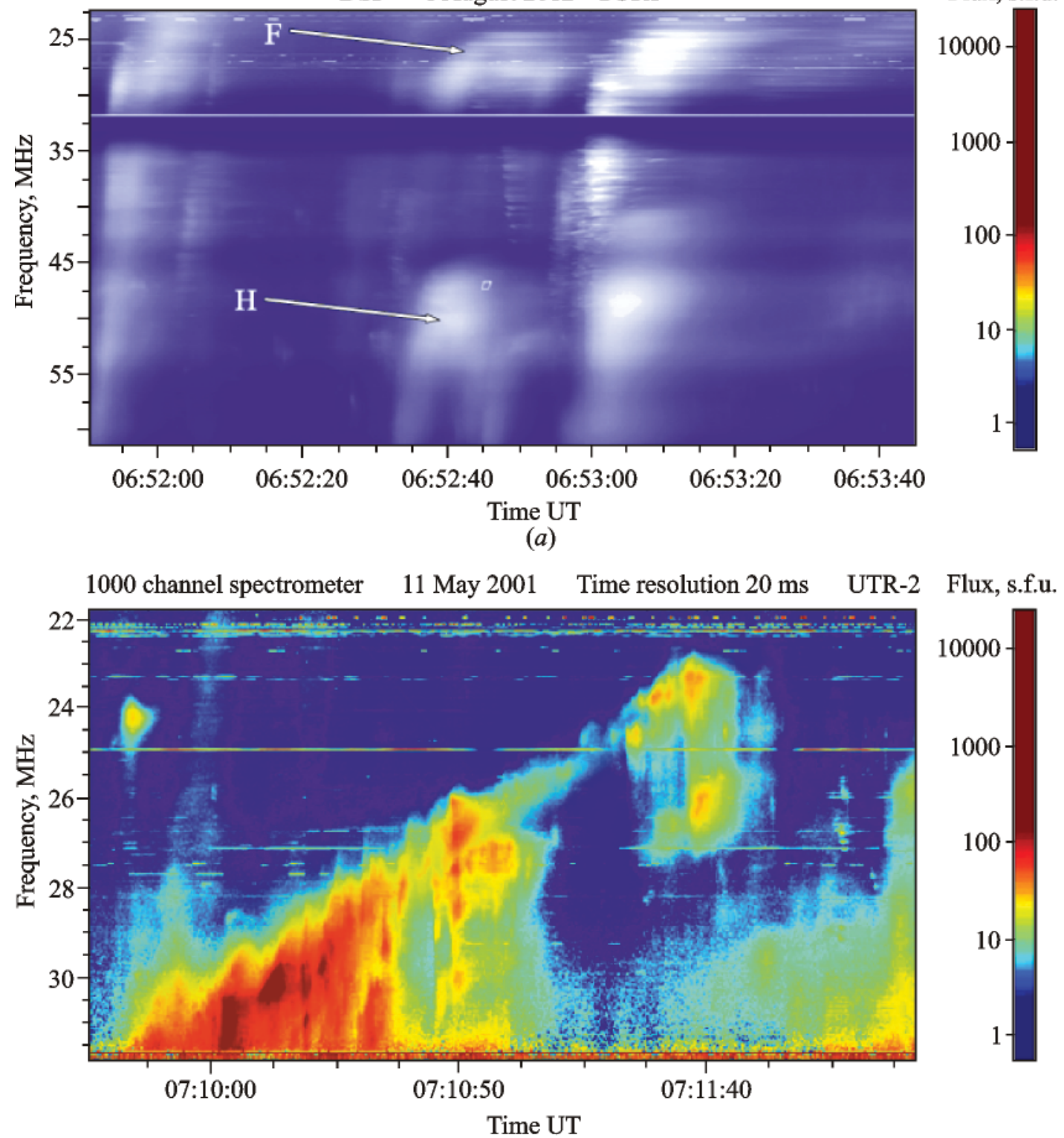

(b)

Fig. 2. U-bursts harmonic pair by the UTR-2 data at the frequencies below $32 \mathrm{MHz}$ and the GURT data at higher frequencies ( $a$ ) and the decameter Type II burst with a fine structure in the form of short irregular sub-bursts $(b)$

allowed to find the relation between the loop height and the confined plasma temperature in dependence on the observed delay between the components of the associated U-burst harmonic pair. According to the model for a given time delay, the hotter the confined plasma, the lower the loop and vice versa.

\section{Type II Bursts}

Though the Type II bursts were classified yet in the 50 s of the last century, in the decameter band these bursts were first observed with the UTR-2 radio tele- scope only in 2001 [23] (Fig. 2(b)), owing to new highly effective back-ends. The Type II bursts main parameters at $10-30 \mathrm{MHz}$ were determined with the UTR-2 radio telescope for the first time [23]. The total duration of the Type II bursts varied from a few minutes up to half an hour while the frequency drift rates were $30-110 \mathrm{kHz} / \mathrm{s}$. Sometimes the Type II bursts did not drift in frequency. It was shown that assuming the plasma emission mechanism the measured drift rates corresponded to the radial velocities of coronal mass ejections (CME) propagating in the corona at 
heliocentric heights of $1.5-3 R_{S}$. A wide continuous working frequency band allowed to retrieve a variety of Type II bursts features such as the band splitting, the harmonic structure consisting of two and even three harmonics of the local plasma frequency and the fine time structure [24]. It was shown that all decameter Type II bursts had a fine structure (Fig. 2(b)). This fine structure could be either of cloudy appearance or in the form of short fast-drifting sub-bursts. The sub-bursts in turn were observed as a non-regular sequence or as a quasi-regular structure called the "herring-bone" structure. Typical durations of non-regular sub-bursts were near $1 \mathrm{~s}$. Their frequency drift rates varied from 0.45 to $3 \mathrm{MHz} / \mathrm{s}$ with both positive and negative drift sign. These observations allowed to suppose that at the shock front the electrons were accelerated not as a whole, but rather as a number of separate beams having different linear sizes, velocities and directions.

For the first time at the decameter band, the "herring-bone" structure of Type II bursts was observed with the UTR-2 [23, 25]. Such bursts consisted of a "back-bone" resembling the normal narrow-band Type II burst, and short sub-bursts drifting from the "back-bone" towards higher and lower frequencies. Extended statistical analysis, made separately for the forward (negative drift rates) and the reverse (positive drift rates) sub-bursts, showed the similarity in their distribution by the absolute drift rates [25]. Moreover, the average drift rate of the reverse sub-bursts appeared to be by $50 \%$ larger than that of the forward sub-burst. Also, for the first time, the dependence of the "herring-bones" drift rates on frequency was obtained. The dependence for the forward sub-bursts appeared to be close to the normal Type III bursts dependence. The drift rates of the reverse sub-bursts showed the less steep dependence on frequency. This fact allowed to suppose that the electron beams associated with the forward and the reverse sub-bursts travelled through the plasmas with different density gradients. Due to unprecedented sensitivity and resolutions, the fine structure of the "herring-bone" structure was discovered [25].

Observations showed that the Type II bursts with this structure did not drift in frequency. Moreover, the "back-bone" of such bursts may have wavelike appearance. This fact allowed to suppose that the Type II bursts with a "herring-bone" structure were generated at the flanks of the shock wave created due to the CME transverse expansion. In this case, the Type
II bursts sources traveled obliquely to the density gradient. It was also assumed that the wave-like variation of the "back-bone" in frequency occurred when the shock wave intersects some dense coronal structures (streamers or loops). Under such assumption, the measured period of these wave-like variations are determined by the transverse sizes of these coronal structures. They were equal to $0.1-0.2 R_{S}$ [23].

For the first time, the main spatial properties of the Type II burst with a "herring-bone" structure were obtained at the decameter band [26]. Spatial analysis of interferometric data allowed to confirm the hypothesis that the sources of different lanes in split Type II bursts were located on the opposite sides of the shock. Also, it was shown that the forward "herring-bone" sub-bursts were generated by the electrons moving outwards the Sun, whereas the reverse sub-bursts were generated by oppositely moving electrons. Angular sizes of the Type II burst sources at the decameter band did not exceed $20^{\prime}$ yielding the effective brightness temperature up to $10^{14} \mathrm{~K}$.

\section{Type IV Bursts}

Type IV bursts (Fig. 3(a)) are those of the main components of the sporadic radio emission of the Sun. As a rule, they are observed simultaneously in a wide frequency band and lasting from half an hour to several hours. New broadband receivers installed at the UTR-2 radio telescope have allowed not only to identify the Type IV bursts for the first time at the decameter band, but also to deeply analyze their properties [24]. The fluxes of the Type IV bursts as a rule vary between 10 and 100 s.f.u. with the maximum values reaching as high as 1000 s.f.u. The typical time profile of the burst reveals rather fast raise and comparatively slow fall of the emission intensity. On the contrary, the polarization degree slowly increases and then rapidly falls. As a rule, the burst intensity peaks earlier than the polarization does. In most cases, the degree of Type IV polarization was about $40 \%$, though there were cases of higher and lower values. The leading edge of the Type IV bursts sometimes drifts from high to low frequencies with the rates typical for the decameter Type II bursts. Such bursts, called the moving Type IV bursts, were usually associated with the CMEs. On the contrary, the stationary Type IV bursts did not show any frequency drifts. Their emission was believed to be connected with coronal loops. The classic scheme, in which the Type IV bursts were usually observed, had the 


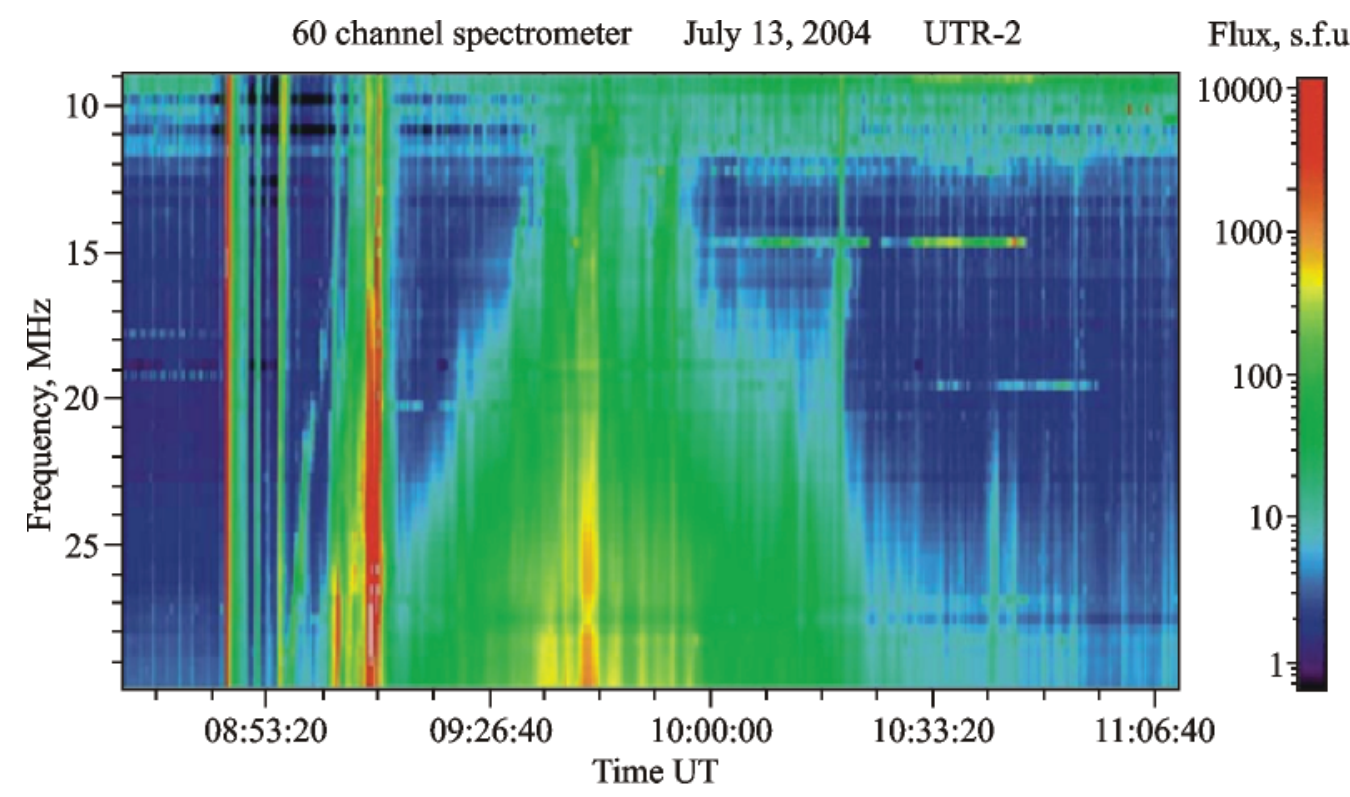

(a)

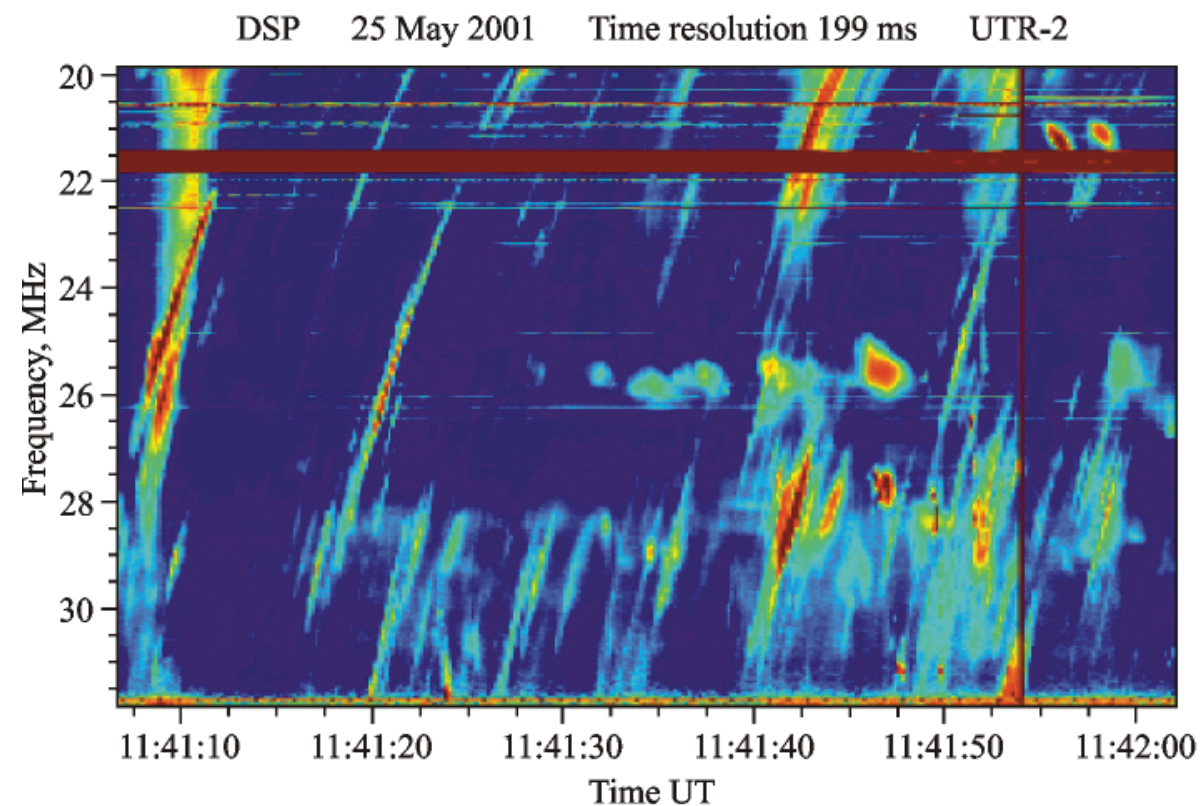

Flux, s.f.u.

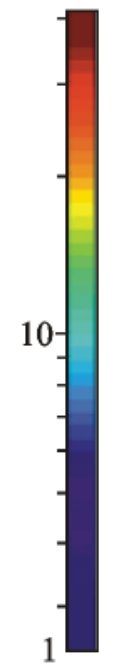

(b)

Fig. 3. The group of Type III bursts (8:53 UT), Type II burst (8:54-9:02 UT), and the moving Type IV burst (9:10-10:30 UT) (a) and the storm of short lifetime decameter S-bursts $(b)$

following sequence. The event started with a group of powerful Type III bursts followed by the Type II burst sometimes revealing a double or even triple harmonic structure. And then, the Type IV burst began (see Fig. 3(a)). Nevertheless, there were exceptions when either the Type III group or the Type II burst or both were absent. This might be connected with the geometry of the source-observer locations or with an energetic issue. All Type IV bursts observed at the decameter band had a fine time-frequency structure in the form of the so-called fiber bursts [27]. Fiber bursts morphologically resembled the normal Type III bursts, at the same time being more diffuse and sometimes having positive drift rates. In addition, the fiber bursts in absorption were also observed including those lasting for several minutes [28]. The socalled "zebra" structure was often observed at decimeter waves. On 22 July 2004, the decameter "zebra" structure was observed with the UTR-2 radio telescope [24]. Unlike its decimeter counterpart, the deca- 
meter "zebra" was quasi-periodic rather in time than in frequency. This unique "zebra" structure was interpreted by the model based on the double plasma resonance [29]. On the one hand, this model explained the periodicity in time, and on the other one, it allowed to independently estimate the magnetic field in the place of generation, as well as the plasma density and magnetic field radial profiles.

\section{Solar S-Bursts}

The solar S-bursts identified by Ellis in 1969 in the frequency band of $40-80 \mathrm{MHz}$ have the appearance of thin emission tracks drifting from high to low frequencies (Fig. 3(b)) with the characteristic drift rates being several times of magnitude smaller than those in the normal Type III bursts. These bursts are observed exclusively at the meter and decameter bands and only under the conditions of increased Type III activity [30-32]. They are the shortest bursts known at the meter and decameter bands with durations smaller than $1 \mathrm{~s}$. The drift rate of one individual S-burst is not constant and decreases with decreasing of frequency. At frequencies below $40 \mathrm{MHz}$, the S-bursts were first observed in May 2001 with the UTR-2 radio telescope [29]. The analysis of three S-burst storms of 2001-2002 allowed to find out that the decameter S-bursts can only be observed when the associated active region is located near the central meridian [32]. It was shown that the parameters of S-bursts of the same storm are distributed in a narrow range, however the difference in bursts of different storms is noticeable. This fact shows that the coronal plasma is different in different times. Thus, the durations of the S-bursts observed in May 2001 were about $0.3-0.4 \mathrm{~s}$, whereas for the storm of July 2002 they equaled to $0.5-0.7 \mathrm{~s}$. The flux densities of the S-bursts, as a rule, do not exceed 20 s.f.u. It was shown that the velocities of the S-burst sources were $5-9 V_{T e}$, where $V_{T e}$ is the electron thermal velocity. It was supposed that these bursts were generated in coalescence of the background Langmuir turbulence and fast magnetosonic waves. The latters, in turn, were excited by the electron beams with the velocity equal to phase and group velocities of these waves [32]. It was found that the instant spectral bandwidth of S-bursts was defined by the angular width of the Langmuir waves and the magnetic field strength in the place of generation in such a way that under the given S-bursts bandwidth, the wider the Langmuir waves spectrum, the lower the magnetic field. In addition, it was shown that the characteristic velocities of the S-bursts sources corresponded to the Langmuir waves isotropy degree of about $50-60^{\circ}$ that yielded the value of the magnetic field of about $2 \mathrm{G}$ at $25 \mathrm{MHz}$ [32]. According to the obtained experimental data, the magnetic field decreased with height.

Joint observations of the faint S-burst storm with the UTR-2 and LOFAR (The Netherlands) radio telescopes have been made on 9 July 2013. Interferometric methods of observations implemented at the UTR-2 allowed to record extremely weak S-bursts with fluxes of an order of 0.2 s.f.u. As a result, more than 1000 S-bursts were identified by the UTR-2 radio telescope in the frequency range of $9-32 \mathrm{MHz}$, whereas only a few tens of S-bursts were observed with the LOFAR in the same frequency band [33]. In addition, the chains consisting of 4-15 short-lifetime S-bursts were observed with the UTR-2 for the first time. These chains had positive drift rates of 1-5 MHz/s. The analysis of the joint observations data made in a wide frequency band allowed to determine the radial profile of the magnetic field at distances of 1.3-2.2 solar radii [34].

\section{Drift Pairs}

The solar bursts, called drift pairs, have been known since the 50s of the last century. As a rule, they consist of two separated in time by $1-2 \mathrm{~s}$ bursts drifting in frequency with the rates of about $\pm(2-8) \mathrm{MHz} / \mathrm{s}$ (Fig. 4(a)). The drift rates of the elements of one individual drift pair are equal and don't depend on frequency. The drift pairs are divided into two groups the forward bursts with negative drift rates and the reverse bursts with a positive drift. According to the previous study, the drift pairs are observed at frequencies below $70 \mathrm{MHz}$ with an evident trend of their occurrence rate to increase towards lower frequencies. From this viewpoint, observations of these bursts with the UTR-2 radio telescope having excellent sensitivity at lowest frequencies were of great interest.

Drift pairs were first observed with the UTR-2 in summer 1974 in two narrow frequency bands of $12-13$ and 24-26 MHz [35]. By that time, no observations at frequencies below $20 \mathrm{MHz}$ were reported. The total amount of the drift pairs observed equaled to 288. A more extended analysis in continuous frequency band $10-30 \mathrm{MHz}$ was made in July 2002 by using new back-ends. The total statistical sample amounted to 774 drift pairs including 404 forward 


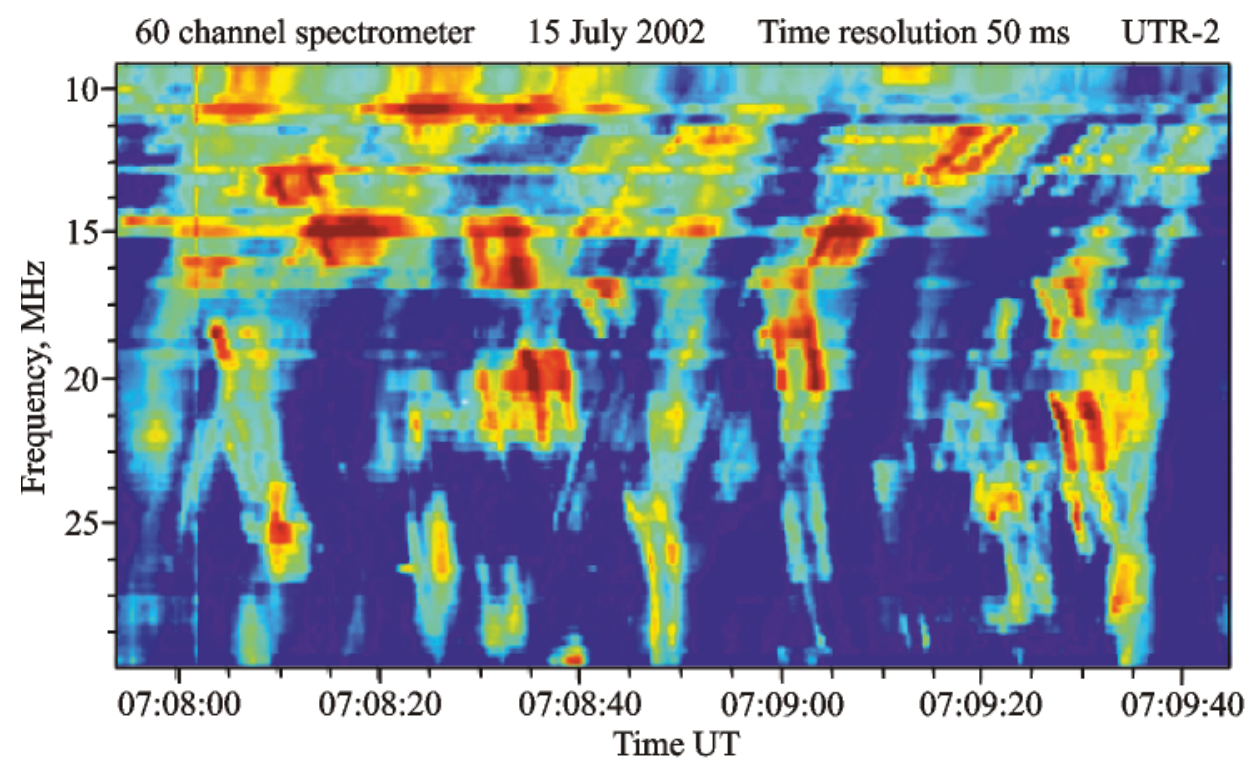

Flux, s.f.u.
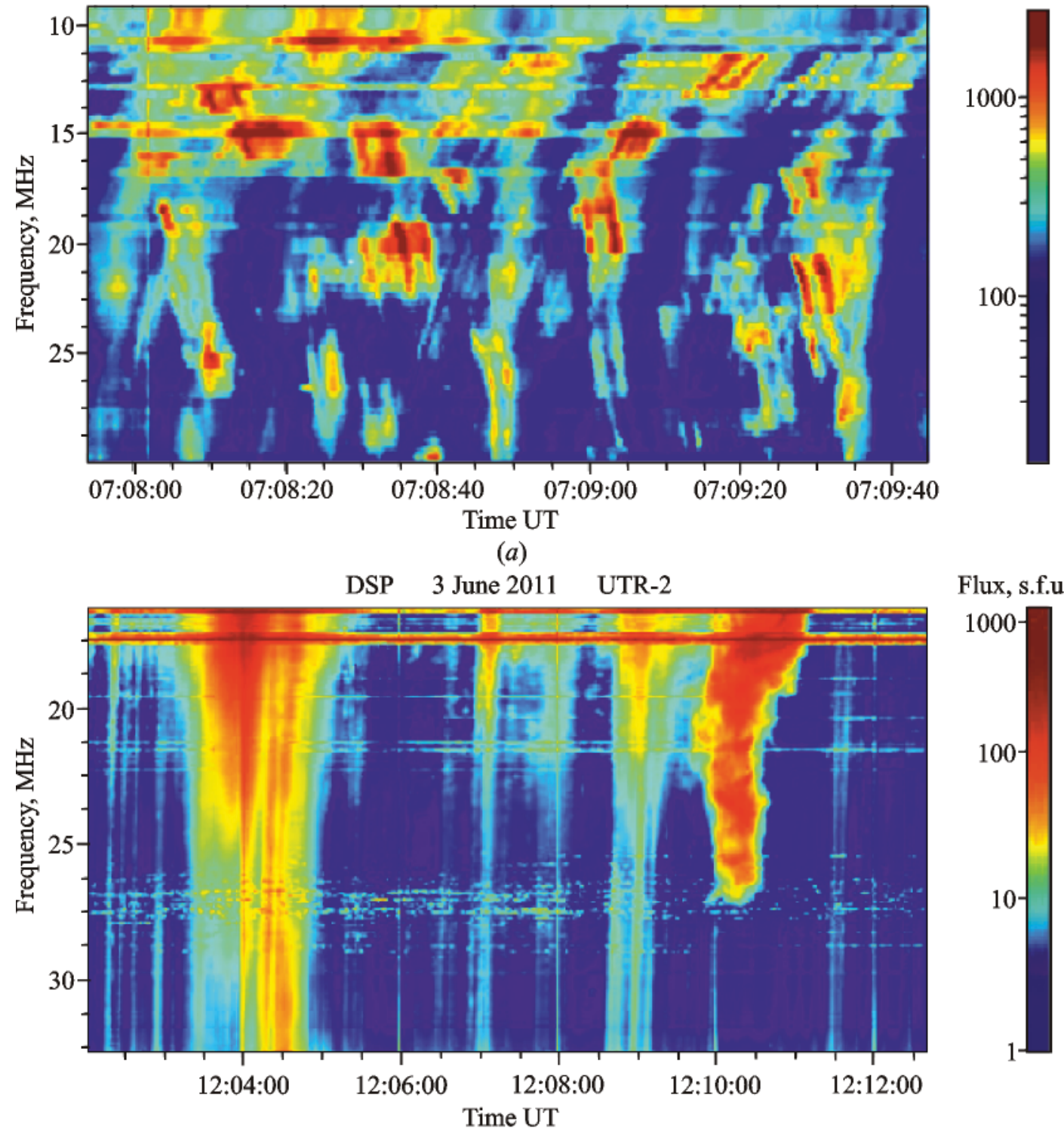

Flux, s.f.u.

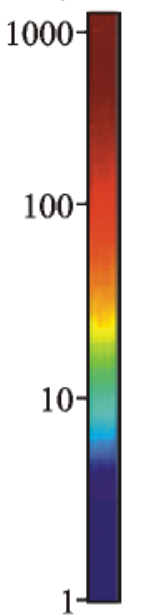

(b)

Fig. 4. The storm of the forward and reverse drift pairs $(a)$ and an unusual "caterpillar" burst (12:10 UT) on the background of the standard Type III bursts $(b)$

bursts. It was shown that the quantitative proportion between the forward and the reverse drift pairs was not a constant value and varied from day to day [36]. It was found that the amount of reverse drift pairs steadily decreased at frequencies below $25 \mathrm{MHz}$, whereas the forward bursts were more uniformly distributed within 10-30 MHz. The forward drift pairs distribution by the drift rates appeared to be much narrower than that for the reverse ones. The average absolute values of the drift rates for the forward and the reverse drift pairs equaled to 1 and $1.5 \mathrm{MHz} / \mathrm{s}$ respectively. Abnormally high drift rates $(\geq 8 \mathrm{MHz} / \mathrm{s})$ were observed in the reverse drift pairs only while extremely low drift rates $(\leq 0.3 \mathrm{MHz} / \mathrm{s})$ were inherent to the forward ones. A wide continuous working frequency band allowed to determine the dependences of drift pairs parameters on frequency. It was in particular shown that the absolute drift rates of both kinds of drift pairs increased with increasing of the burst median frequency. Moreover, this dependence for the reverse bursts was steeper than that for the forward ones. It was found that the value of the delay between the pair elements had a low dispersion averaging $1.7 \mathrm{~s}$ for the forward and $2 \mathrm{~s}$ for the reverse bursts. 
The given facts made interpretation of these bursts difficult. One of the suggested models was based on the double plasma resonance theory according to which the generation occurred at specific ratio between the local plasma frequency and the electron cyclotron frequency [35]. However, the high resolution observations of 2002 showed an exclusive morphological similarity of the two elements within each pair.

It was determined that the mean drift rates of drift pairs corresponded to the radial source velocities of $(1-2) \cdot 10^{9} \mathrm{~cm} / \mathrm{s}$. It was substantially smaller than the Type III electrons velocity and considerably higher than the thermal electron velocity in the corona. However, this velocity was close to the phase and the group velocities of the fast magnetosonic waves. This fact gives reasons to suppose a mechanism, in which both elements of the drift pairs were generated in coalescence of the background Langmuir turbulence with the fast magnetosonic waves, when the Cherenkov resonance conditions were met, i.e. the velocity of the fast electron beam equaled the phase and the group velocities of the fast magnetosonic wave. Then the two elements of the pair could be generated as the $\mathrm{O}$ and the $\mathrm{X}$ mode electromagnetic waves respectively and the time delay appeared due to different group velocities of the $\mathrm{O}$ and the $\mathrm{X}$ waves near the emission source [36].

\section{Spikes}

The spikes belong to the class of the fine structured solar radio bursts. Melnik et al. [37], defined the spikes as the bursts observed exclusively on the background of increased solar activity and regardless the frequency band, short durations, and narrow spectral bandwidths compared with other types of solar bursts. One more spikes distinction is their chaotic distribution on the dynamic spectrum (Fig. 1(b)). Apparently the possibility of recording and identification of spikes with the UTR-2 radio telescope appeared when the DSP and DSPZ broadband digital receivers were installed $[37,38]$. Analysis of the obtained data have shown that at the decameter band the spikes were similar to the striae by a number of parameters, such as mean durations, bandwidths and fluxes, which equaled to $1 \mathrm{~s}$, $60 \mathrm{kHz}$ and 70 s.f.u. respectively. The dependences of these parameters on frequency obtained from the extended statistical sample differed insignificantly for the two cognate bursts.

The spikes durations decreased with frequency as $d \sim f^{-1}$, and the bandwidths linearly increased as
$\Delta f \sim f$. No systematic dependence of flux density on frequency was found. One more important and confirmed fact was the stability of the spikes durations and bandwidths for different days and even years of observations. This fact evidenced that the specific conditions must be satisfied to enable spikes generation. To find these conditions it was supposed that the spikes durations were apparently determined by the particle collision time (and thus by the temperature), and spectral bandwidth was determined by the local magnetic field [37]. The model suggested have allowed to obtain the temperature profile at distances $1.6-3.3 R_{S}$. This profile showed that the temperature decreased at these distances from 0.6 to $0.1 \mathrm{MK}$ [38]. At the same time, the magnetic field at these distances equaled to $1.6-2$ G. The obtained results give reasons to suppose that spikes and striae are apparently the same type of solar bursts and thus both could be used as a tool for remote diagnostics of outer solar corona parameters. However, the problem of different character of their location on the dynamic spectrum needs further study.

\section{Unusual Bursts}

Starting from the very first observations of the solar radio emission with the UTR-2 radio telescope there were many attempts to detect the unusual events at the decameter band. It was reasonable due to the UTR-2 outstanding characteristics - wide frequency band, high sensitivity at the lowest frequencies and rather narrow antenna beam comparable to the size of the Sun. In the 70-80s of the last century, the observations of unusual slowly varying radio emission sources were made. This emission was thought to be connected with the coronal condensations at $0.05-0.2 R_{S}$ above the active regions. Such emission at the centimeter and decimeter bands was reliably recorded and thus it was believed to exist at the meter and decameter bands and even was detected by the Clark Lake radio telescope (USA) at the frequency of $26.3 \mathrm{MHz}$. The lifetime of these slowly varying components lasted from several days up to $2-3$ months. Repeated attempts to detect this emission with the UTR-2 radio telescope were unsuccessful [39].

At the same time, the unusual short lifetime bursts were repeatedly observed at the decameter band. One of the brightest examples of such bursts was the burst resembling a "caterpillar" on the dynamic spectrum (see Fig. 4(b)). The distinctive feature of this burst was a high frequency cut-off [40]. For the 
observed burst, the cut-off frequency was $28 \mathrm{MHz}$. In addition, the burst duration equaled to $80 \mathrm{~s}$, being several times of magnitude longer than that of the typical Type III bursts. The burst had the negative frequency drift rate at frequencies below $22 \mathrm{MHz}$ and the positive drift at higher frequencies. The radio emission flux density of the burst was high, reaching 103 s.f.u. It was weakly polarized with the degree not exceeding $10 \%$. Similar bursts have been repeatedly observed with the UTR-2 [41] and URAN-2 [40] radio telescopes (Ukraine). The theory of these unusual bursts generation was suggested, in which the radio emission of these bursts being generated in the sources behind the solar limb passed through the corona on its way to the observer [40]. In this case, the value of the cut-off frequency would depend on the direction in which the source moved.

Another explanation of this phenomenon can be done in the framework of a recently suggested theory of solar corona [42], in which unlike in standard models, the temperature is supposed to change with distance from the Sun. One of the solutions of the corresponding hydrodynamic equations is the discontinuous solution similar to a shock wave. As is known, densities of the coronal plasma at the both sides of the break can differ considerably. In this case, if the electron beam responsible for the Type III burst intersects this break, then a burst with the cutoff (see, Fig. 4(b)) is observed. The cut-off can occur both at high and low frequencies.

\section{Quiet Sun}

Together with the sporadic component of the solar radio emission, the continual thermal radio emission was also studied. The broadband thermal radio emission of the Sun originates due to the particles collisions in plasma. From this point of view, the decameter band is of great importance because the radio emission of this band carries the information about the state of the outer corona at distances of $1.5-3 R_{S}$, which cannot be studied by any other method.

The first observations of the solar continual radio emission with the UTR-2 radio telescope were made in July 1976 at fixed frequencies of 20 and $25 \mathrm{MHz}$ [43]. For the first time, at such low frequencies a two-dimensional distribution of the effective brightness temperature of the solar thermal radio emission, as well as its total flux and the source size, were detected (measurements at $20 \mathrm{MHz}$ were made in the equatorial direction only). It was found that during the maximum of the solar activity cycle the total flux and angular sizes of the radio Sun were not constant and changed from day to day. Thus, the total flux varied from 770 to $990 \mathrm{Jy}$ while the sizes were within $37-43^{\prime}$ in the polar direction and $56-58^{\prime}$ along the equator. It was confirmed that similarly to the higher frequencies the radio Sun at the decameter band has an elliptical shape with the mean compression factor of $0.72[43,44]$.

Observations of the solar thermal radio emission in a wide continuous frequency band of $16-33 \mathrm{MHz}$ during the minimum phase of solar cycle were made in 2010 [45]. The spectral index of the thermal decameter radio emission was found to be -2.1 . The radio Sun sizes were measured. It was shown that the polar and equatorial sizes of the Sun increased with decreasing of frequency following the power law with indexes -0.27 and -0.26 respectively. In addition, these dependences appeared to be very close to the plasma frequency dependence on the distance in undisturbed corona model by Baumbach-Allen [46]. The effective brightness temperature of the solar thermal radio emission was found to be equal to $2 \cdot 10^{5} \mathrm{~K}$, which is several times smaller in magnitude than the kinetic plasma temperature. This fact was explained by the electromagnetic wave scattering in the coronal plasma.

It was shown that the UTR-2 radio telescope working as a short-baseline interferometer was an effective tool for determining the coronal plasma parameters at distances $2-3 R_{S}[47]$.

\section{Conclusions}

The results obtained with the UTR-2 radio telescope for 50 years of observations of solar radio emission are new and foreground. This applies primarily to observations of the Type II and Type IV bursts at the frequencies of $10-30 \mathrm{MHz}$, short decameter S-bursts, drift pairs and spikes, distinguishing of fine and superfine structures in the Type III, Type II, and Type IV bursts, U-, J-, and S-bursts, discoveries of new types of bursts such as bursts in absorption and "caterpillar" bursts with high frequency cut-off. Solar observations in heliographic and interferometric modes of the UTR-2 operation allowed to obtain the pioneer results, which were extremely important for understanding the processes of radio emission generation and its propagation in the solar corona through the analysis of the sizes and locations of 
the emission sources within the frequency band of 10-30 MHz. Further observations of solar radio emission jointly with the other ground-based radio telescopes such as URAN-2, NDA, LOFAR, NenuFAR, LWA, as well as the space-borne instruments Parker Solar Probe, STEREO and Solar Orbiter, will allow to considerably improve our understanding of both the generation processes in a wide frequency band and the physics of solar flares, solar corona, coronal mass ejections and their effect on space weather.

\section{REFERENCES}

1. ABRANIN, E. P., BAZELYAN, L. L., RAPOPORT, V. O. and TSYBKO, YA. G., 1980. Variations of type III burst parameters during a decametric solar storm. Sol. Phys. vol. 66, is. 2, pp. 333-346. DOI: 10.1007/BF00150589

2. ABRANIN, É. P., BAZELYAN, L. L. and TSYBKO, YA. G., 1990. Stability of the parameters of decameter type III bursts over the 11-year solar activity cycle. Rates of frequency drift of radio burst. Sov. Astron. vol. 34, no. 1, p. 74-78.

3. ABRANIN, É. P. and BAZELYAN, L. L., 1993. Harmonic structure of decameter-wave type III emission and group delay of radio waves in the solar corona. Astron. Rep. vol. 37, is. 4 , pp. $438-444$.

4. ABRANIN, E. P., BAZELYAN, L. L., GONCHAROV, N. YU., ZAITSEV, V. V., ZINICHEV, V. A., RAPOPORT, V. O. and TSYBKO, YA. G., 1980. Positions of solar storm burst sources by observations with a heliograph based on the UTR-2 antenna at $25 \mathrm{MHz}$. Sol. Phys. vol. 66, is. 2, pp. 393-409. DOI: 10.1007/BF00150593

5. ITKINA, M. A., LEVIN, B. N. and TSYBKO, YA. G., 1993. On the radio wave group delay in the solar corona for the case of decameter type III bursts. Astron. Astrophys. vol. 279, no. 1, pp. 235-242.

6. ABRANIN, E. P., BAZELYAN, L. L., GONCHAROV, N. Yu., ZAITSEV, V. V., ZINICHEV, V. A., RAPOPORT, V. A. and TSYBKO, YA. G., 1976. Angular sizes of sources of solar radio burst in the decameter range. Sov. Astron. vol. 19, no. 5, pp. 602-605.

7. MEL'NIK, V. N., KONOVALENKO, A. A., ABRANIN, E. P., DOROVSKYY, V. V., STANISLAVSKY, A. A., RUCKER, H. O. and LECACHEUX, A., 2005. Solar sporadic radio emission in the decametre waveband. Astron. Astrophys. Trans. vol. 24, is. 5, pp. 391-401. DOI: $10.1080 / 10556790600568854$

8. MEL'NIK, V. N., KONOVALENKO, A. A., RUCKER, H. O., RUTKEVYCH, B. P., DOROVSKYY, V. V., ABRANIN, E. P., BRAZHENKO, A. I., STANISLAVSKII, A. A. and LECACHEUX, A., 2008. Decameter Type III-Like Bursts. Sol. Phys. vol. 250, is. 1, pp. 133-145. DOI: 10.1007/ s11207-008-9166-z

9. MELNIK, V. N., BRAZHENKO, A. I., KONOVALENKO, A. A., BRIAND, C., DOROVSKYY, V. V., ZARKA, P., FRANTSUZENKO, A. V., RUCKER, H. O., RUTKEVYCH, B. P., PANCHENKO, M., DENIS, L., ZAQARASHVILI, T. and SHERGELASHVILI, B., 2015. Decameter Type III Bursts with Changing Frequency Drift-Rate Signs.
Sol. Phys. vol. 290, is. 1, pp. 193-203. DOI: 10.1007/s11207014-0577-8

10. MELNIK, V. N., KONOVALENKO, A. A., RUCKER, H. O., BOIKO, A. I., DOROVSKYY, V. V., ABRANIN, E. P. and LECACHEUX, A., 2011. Observations of Powerful Type III Bursts in the Frequency Range 10-30 MHz. Sol. Phys. vol. 269 , is. 2, pp. 335-350. DOI: $10.1007 / \mathrm{s} 11207-010-$ 9703-4

11. DOROVSKYY, V. V., MELNIK, V. N., KONOVALENKO, A. A., RUCKER, H. O., ABRANIN, E. P. and LECACHEUX, A., 2011. Unusual Type III Bursts at the Decameter Wavelengths. In: H. O. RUCKER, W. S. KURTH, P. LOUARN, and G. FISCHER, eds. Planetary Radio Emissions VII: Proceedings of the 7th International Workshop on Planetary, Solar and Heliospheric Radio Emissions. Vienna, Austria: Austrian Academy of Sciences Press, pp. 359-366. DOI: $10.1553 /$ PRE7s359

12. RUTKEVYCH, B. P. and MELNIK, V. N., 2011. Numerical Simulation of the Propagation of Type III Radio Emission. In: H. O. RUCKER, W. S. KURTH, P. LOUARN, and G. FISCHER, eds. Planetary Radio Emissions VII: Proceedings of the 7th International Workshop on Planetary, Solar and Heliospheric Radio Emissions. Vienna, Austria: Austrian Academy of Sciences Press, pp. 391-398. DOI: 10.1553/ PRE7s391

13. MELNIK, V., SHEPELEV, V., BRAZHENKO, A., DOROVSKYY, V., RUCKER, H. and POEDS, S., 2017. Interferometer Observations of Solar Type III Bursts by the Radio Telescope UTR-2. Sun Geosph. vol. 12, no. 2, pp. 105-109.

14. BASELYAN, L. L, GONCHAROV, N. YU., ZAITSEV, V. V., ZINICHEV, V. A., RAPOPORT, V. O. and TSYBKO, YA. G., 1974. Frequency and Time Splitting of Decameter Solar Radio Bursts. II: Chains. Sol. Phys. vol. 39, is. 1, pp. 223-231. DOI: 10.1007/BF00154983

15. BASELYAN, L. L, GONCHAROV, N. YU., ZAITSEV, V. V., ZINICHEV, V. A., RAPOPORT, V. O. and TSYBKO, YA. G., 1974. Frequency and Time Splitting of Decameter Solar Radio Bursts. I: Elementary events. Sol. Phys. vol. 39, is. 1, pp. 213-222. DOI: 10.1007/BF00154982

16. ABRANIN, E. P., BAZELYAN, L. L., GONCHAROV, N. YU., ZAITSEV, V. V., ZINICHEV, V. A., RAPOPORT, V. O. and TSYBKO, YA. G., 1978. Angular sizes of stria-burst sources in the range $24-26 \mathrm{MHz}$. Sol. Phys. vol. 57, is. 1, pp. 229-235. DOI: 10.1007/BF00152056

17. ABRANIN, E. P., BAZELYAN, L. L. and TSYBKO, YA. G., 1984. Harmonic relation of type IIIb-III solar radio bursts in $6.25,12.5$, and $25.0 \mathrm{MHz}$ octaves. Sol. Phys. vol. 91, is. 2, pp. 377-381. DOI: 10.1007/BF00146306

18. TSYBKO, YA. G., 1984. Harmonic components of decametric solar radio bursts. Sol. Phys. vol. 92, is. 1-2, pp. 299-315. DOI: 10.1007/BF00157253

19. MELNIK, V. N., RUCKER, H. O., KONOVALENKO, A. A., SHEVCHUK, N. V., ABRANIN, E. P., DOROVSKYY, V. V. and LECACHEUX, A., 2010. Type IIIb bursts and their fine structure in frequency band 18-30 MHz. AIP Conf. Proc. vol. 1206, is. 1, pp. 445-449. DOI: $10.1063 / 1.3292552$

20. SHEVCHUK, M. V., MELNIK, V. N., POEDTS, S., DOROVSKYY, V. V., MAGDALENIC, J. and KONOVALENKO, A. A., 2018. On the Observational Properties of the Decameter Striae. In: 2018 2nd URSI Atlantic Radio 
Science Meeting (AT-RASC) Proceedings. Meloneras, Spain, 28 May - 1 June, 2018. DOI: 10.23919/URSI-ATRASC.2018.8471315

21. DOROVSKYY, V. V., MELNIK, V. N., KONOVALENKO, O. O., RUKER, H. O., ABRANIN, E. P. and LECACHEUX, A., 2010. Solar U- and J-Bursts at the Decameter Waves. Radio Phys. Radio Astron. vol. 15, no. 1, pp. 5-14. (in Russian).

22. DOROVSKYY, V. V., MELNIK, V. N., KONOVALENKO, A. A., BUBNOV, I. N., GRIDIN, A. A., SHEVCHUK, N. V., RUCKER, H. O., POEDTS, S. and PANCHENKO, M., 2015. Decameter U-burst Harmonic Pair from a High Loop. Sol. Phys. vol. 290, is. 1, pp. 181-192. DOI: $10.1007 / \mathrm{s} 11207-014-0615-6$

23. MEL'NIK, V. N., KONOVALENKO, A. A., RUCKER, H. O., STANISLAVSKY, A. A., ABRANIN, E. P., LECACHEUX, A., MANN, G., WARMUTH, A., ZAITSEV, V. V., BOUDJADA, M. Y., DOROVSKII, V. V., ZAHARENKO, V. V., LISACHENKO, V. N. and ROSOLEN, C., 2004. Observations of Solar Type II bursts at frequencies 10-30 MHz. Sol. Phys. vol. 222, is. 1, pp. 151-166. DOI: 10.1023/B:SOLA.0000036854.66380.a4

24. MEL'NIK, V. N., RUCKER, H. O., KONOVALENKO, A. A., DOROVSKYY, V. V., ABRANIN, E. P., BRAZHENKO, A. I., THIDE, B. and STANISLAVSKYY, A. A., 2008. Solar Type IV Bursts at Frequencies 10-30 MHz. In: P. WANG, ed. Solar Physics Research Trends. New York: Nova Science Publ., pp. 287-325.

25. DOROVSKYY, V. V., MELNIK, V. N., KONOVALENKO, A. A., BRAZHENKO, A. I., PANCHENKO, M., POEDTS, S. and MYKHAYLOV, V. A., 2015. Fine and Superfine Structure of the Decameter-Hectometer Type II Burst on 7 June 2011. Sol. Phys. vol. 290, is. 7, pp. 2031-2042. DOI: 10.1007/s11207-015-0725-9

26. DOROVSKYY, V., MELNIK, V., KONOVALENKO, A., BRAZHENKO, A. and RUCKER, H., 2017. Spatial properties of the complex decameter type II burst observed on 31 May 2013. Sun Geosph. vol. 13, no. 1, pp. 25-30.

27. ANTONOV, A. V., MELNIK, V. N., KONOVALENKO, A. A., DOROVSKYY, V. V., RUCKER, H. O., ZAQARASHVILI, T., STANISLAVSKY, A. A. and KOVAL, A. A., 2014. Decameter Type IV Bursts, FiberBursts and Type III Bursts Associated with Group of Solar Active Regions. Radio Phys. Radio Astron. vol. 19, no. 4, p. 295-306. DOI: $10.15407 /$ rpra19.04.295

28. KONOVALENKO, A. A., STANISLAVSKY, A. A., ABRANIN, E. P., DOROVSKY, V. V., MEL'NIK, V. N., KAISER, M. L., LECACHEUX, A. and RUCKER, H. O., 2007. Absorption in Burst Emission. Sol. Phys. vol. 245, is. 2, pp. 345-354. DOI: 10.1007/s11207-007-9049-8

29. ZLOTNIK, E. Y., ZAITSEV, V. V., MELNIK, V. N., KONOVALENKO, A. A. and DOROVSKYY, V. V., 2015. 'Fingerprint' Fine Structure in the Solar Decametric Radio Spectrum. Sol. Phys. vol. 290, is. 7, pp. 2013-2030. DOI: 10.1007/s11207-015-0724-X

30. DOROVSKYY, V. V., MEL'NIK, V. N., KONOVALENKO, A. A., RUCKER, H. O., ABRANIN, E. P. and LECACHEUX, A., 2006. Observations of Solar S-bursts at the decameter wavelengths. In: H. O. RUCKER, W. S. KURTH, and G. Mann, eds. Planetary Radio Emissions VI: Proceedings of the 6th International Workshop on Planetary,
Solar and Heliospheric Radio Emissions. Vienna, Austria: Austrian Academy of Sciences Press, pp. 383-390.

31. BRIAND, C., ZASLAVSKY, A., MAKSIMOVIC, M., ZARKA, P., LECACHEUX, A., RUCKER, H. O., KONOVALENKO, A. A., ABRANIN, E. P., DOROVSKY, V. V., STANISLAVSKY, A. A. and MELNIK, V. N., 2008. Faint solar radio structures from decametric observations. Astron. Astrophys. vol. 490, no. 1, pp. 339-344. DOI: 10.1051/00046361:200809842

32. MELNIK, V. N., KONOVALENKO, A. A., RUCKER, H. O., DOROVSKYY, V. V., ABRANIN, E. P., LECACHEUX, A. and LONSKAYA, A. S., 2010. Solar S-bursts at Frequencies of 10 - 30 MHz. Sol. Phys. vol. 264, is. 1, pp. 103-117. DOI: 10.1007/s11207-010-9571-y

33. DOROVSKYY, V. V., MELNIK, V. N., KONOVALENKO, A. A., BRAZHENKO, A., POEDTS, S., RUCKER, H. O. and PANCHENKO, M., 2017. Properties of groups of solar S-bursts in the decameter band. In: G. FISHER, G. MANN, M. PANCHENKO, and P. ZARKA, eds. Planetary Radio Emissions VIII: Proceedings of the 8th International Workshop on Planetary, Solar and Heliospheric Radio Emissions. Vienna, Austria: Austrian Academy of Sciences Press, pp. 369-378.

34. ClARKE, B. P., MOROSAN, D. E., GALLAGHER, P. T., DOROVSKYY, V. V., KONOVALENKO, A. A. and CARLEY, E. P., 2019. Properties and magnetic origins of solar S-bursts. Astron. Astrophys. vol. 622, id. A204. DOI: 10.1051/0004-6361/201833939

35. ABRANIN, E. P., BAZELYAN, L. L., GONCHAROV, N. YU., ZAITSEV, V. V., ZINICHEV, V. A., LEVIN, B. N., RAPOPORT, V. O. and TSYBKO, YA. G., 1977. Some results of observations of solar radio bursts of the "drifting pairs" type near frequencies of 25 and $12.5 \mathrm{MHz}$. Sov. Astron. vol. 21, no. 1, pp. 82-88.

36. MELNIK, V. N., KONOVALENKO, A. A., DOROVSKYY, V. V., RUCKER, H. O., ABRANIN, E. P., LISACHENKO, V. N. and LECACHEUX, A., 2005. Solar Drift Pair Bursts in the Decameter Range. Sol. Phys. vol. 231, is. $1-2$, pp. 143-155. DOI: $10.1007 / \mathrm{s} 11207-005-8272-4$

37. MELNIK, V. N., SHEVCHUK, N. V., KONOVALENKO, A. A., RUCKER, H. O., DOROVSKYY, V. V., POEDTS, S. and LECACHEUX, A., 2014. Solar Decameter Spikes. Sol. Phys. vol. 289, is. 5, pp. 1701-1714. DOI: 10.1007/s11207-013-0434-1

38. SHEVCHUK, N. V., MELNIK, V. N., POEDTS, S., DOROVSKYY, V. V., MAGDALENIC, J., KONOVALENKO, A. A., BRAZHENKO, A. I., BRIAND, C., FRANTSUZENKO, A. V., RUCKER, H. O. and ZARKA, P., 2016. The Storm of Decameter Spikes During the Event of 14 June 2012. Sol. Phys. vol. 291, is.1, pp. 211-228. DOI: $10.1007 /$ s11207-015-0799-4

39. BAZELYAN, L. L., 1986. Slowly varying local solar decameter sources? Sov. Astron. Lett. vol. 12, no. 2, pp. 110-112.

40. MELNIK, V. N., BRAZHENKO, A. I., KONOVALENKO, A. A., RUCKER, H. O., FRANTSUZENKO, A. V., DOROVSKYY, V. V., PANCHENKO, M. and STANISLAVSKYY, A. A., 2014. Unusual Solar Radio Burst Observed at Decameter Wavelengths. Sol. Phys. vol. 289, is. 1, pp. 263-278. DOI: 10.1007/s11207-013-0328-2

41. STANISLAVSKY, A. A., 2017. Solar type III bursts with high-frequency cut-off. Astronomische Nachrichten. vol. 338, is. 4, pp. 407-412. DOI: 10.1002/asna.201613141 
42. SHERGELASHVILI, B. M., MELNIK, V. N., DIDIDZE, G., FICHTNER, H., BRENN, G., POEDTS, S., FOYSI, H., KHODACHENKO, M. L. and ZAQARASHVILI, T. V., 2020. A new class of discontinuous solar wind solutions. Mon. Not. R. Astron. Soc. vol. 496, is. 2, pp. 1023-1034. DOI: $10.1093 / \mathrm{mnras} / \mathrm{staa} 1396$

43. ABRANIN, E. P. and BAZELYAN, L. L., 1986. Decametric radiation of the quiet Sun. Kharkiv, Ukraine. Institute for Radiophysics and Electronics, Academy of Sciences of Ukrainian SSR. Preprint № 304, 32 p. (in Russian).

44. STANISLAVSKY, A. A. and KOVAL, A. A., 2013. Solar Corona Elliptical Model. Radio Phys. Radio Astron. vol. 18, no. 1, p. 3-11. (in Russian).

45. BRAZHENKO, A. I., KOVAL, A. A., KONOVALENKO, A. A., STANISLAVSKY, A. A., ABRANIN, E. P., DOROVSKYY, V. V., MELNIK, V. M., VASHCHISHIN, R. V., FRANTSUZENKO, A. V. and BORYSYUK, O. V., 2012. Peculiarity of Continuum Emission from Upper Corona of the Sun at Decameter Wavelengths. Radio Phys. Radio Astron. vol. 17, no. 1, p. 3-14. (in Russian).

46. MELNIK, V. N., SHEPELEV, V. A., POEDTS, S., DOROVSKYY, V. V., BRAZHENKO, A. I. and RUCKER, H. O., 2018. Interferometric Observations of the Quiet Sun at 20 and $25 \mathrm{MHz}$ in May 2014. Sol. Phys. vol. 293, is. 6, id. 97. DOI: $10.1007 / \mathrm{s} 11207-018-1316-3$

47. SHEPELEV, V. A., 2015. Determination of Angular Parameters of the Sources of Solar Radio Emission at Decameter Wavelengths. Radio Phys. Radio Astron. vol. 20, no. 1, pp. 20-29. (in Russian). DOI: 10.15407/rpra20.01.020

В. М. Мельник ${ }^{1}$, О. О. Коноваленко ${ }^{1}$, В. В. Доровський ${ }^{1}$, A. Лекашо ${ }^{2}$, Х. О. Рукер ${ }^{3}$, М. В. Шевчук ${ }^{1}$

${ }^{1}$ Радіоастрономічний інститут НАН України, вул. Мистецтв, 4, м. Харків, 61002, Україна

2 Лабораторія космічних досліджень

і астрофізичного приладобудування,

Паризька обсерваторія, медонський філіал, пл. Жюля Жансена, 5, Медон, F-92195, Франція

${ }^{3}$ Інститут космічних досліджень

Австрійської академії наук,

вул. Шмідльштрасе, 6, м. Грац, 8042, Австрія

\section{ДОСЛІДЖЕННЯ СОНЯЧНОГО ДЕКАМЕТРОВОГО РАДІОВИПРОМІНЮВАННЯ ЗА ДОПОМОГОЮ РАДІОТЕЛЕСКОПА УТР-2}

Предмет і мета роботи: Огляд наукових статей щодо вивчення сонячного декаметрового радіовипромінювання за допомогою найбільшого у світі радіотелескопа УТР-2, опублікованих за останні 50 років.
Методи і методологія: Вивчення та аналіз наукових публікацій щодо як спорадичного, так і спокійного (теплового) радіовипромінювання Сонця, зареєстрованого на радіотелескопі УТР-2 (Україна) у декаметровому діапазоні довжин хвиль.

Результати: Наведено найважливіші результати спостережень та теоретичних досліджень декаметрового радіовипромінювання Сонця, отримані у Радіоастрономічному інституті НАН України за останні 50 років.

Висновки: Уперше на частотах нижче 30 МГц спостерігались сплески II типу, сплески IV типу, S-сплески, спайки та дрейфуючі пари. Отримано залежності параметрів цих сплесків від частоти на частотах $9 \div 30$ МГц та запропоновано моделі їх генерації. Крім того, завдяки високій чутливості та високій частотно-часовій роздільній здатності радіотелескопа УТР-2 були уперше зареєстровані тонкі частотно-часові структури у сплесків III типу, сплесків II типу, сплесків IV типу, U- та J-сплесків, дрейфуючих пар та S-сплесків. Уперше ідентифіковано надтонку структуру сплесків II типу з “ялинковою” структурою. Були відкриті нові типи сплесків: сплески типу “caterpillar" та "dog-leg”, сплески III типу з розпадом, сплески III типу зі змінним знаком частотного дрейфу, III-like сплески, Jb- та Ub-сплески тощо. Запропоновано інтерпретацію виникнення надзвичайно великого частотного дрейфу сплесків III типу та швидкості частотного дрейфу 3 різним знаком. За залежністю тривалості спайків від частоти визначений температурний профіль корони на висотах $(1.5 \div 3) R_{S}$.

Використання геліографічних та інтерферометричних методів дало змогу почати дослідження просторових характеристик - розмірів та місцезнаходження джерел випромінювання сплесків. Так, показано, що тривалість сплесків III типу у декаметровому діапазоні довжин хвиль визначається перш за все розміром джерела випромінювання, тоді як тривалість спайків визначається часом зіткнень частинок у плазмі. Експериментально доведено, що ефективні яскравісні температури джерел сонячного спорадичного радіовипромінювання у декаметровому діапазоні можуть сягати значень $10^{14} \div 10^{15}$ К. Крім того, було знайдено, що радіуси спокійного Сонця на частотах 20 та 25 МГц близькі до таких відстаней від Сонця, на яких місцеві плазмові частоти дорівнюють відповідним частотам радіовипромінювання в моделі Баумбаха-Аллена.

Ключові слова: УТР-2, Сонце, декаметрове радіовипромінювання, радіосплески, корона

Received 19.10.2020 